\title{
High laryngeal mask airway pressures resulting from nitrous oxide do not increase pharyngeal mucosal injury in dogs
}

\author{
[Les pressions élevées du masque laryngé, causées par le protoxyde d'azote, \\ n'augmentent pas les lésions muqueuses chez les chiens]
}

Tânia Mara Vilela Abud MD, ${ }^{*}$ José Reinaldo Cerqueira Braz MD PhD, ${ }^{*}$ Regina Helena Garcia Martins MD PhD, $\dagger$ Elisa Aparecida Gregório PhD, $\ddagger$ João Carlos Saldanha MD\$

Purpose: During general anesthesia, nitrous oxide $\left(\mathrm{N}_{2} \mathrm{O}\right)$ diffuses rapidly into the air-filled laryngeal mask airway (LMA) cuff, increasing intracuff pressure. There is no clear correlation between LMA intracuff pressure and pressure on the pharynx. We have studied the effects of high LMA intracuff pressures secondary to $\mathrm{N}_{2} \mathrm{O}$ on the pharyngeal mucosa of dogs.

Methods: Sixteen mongrel dogs were randomly allocated to two groups: GI (intracuff volume, $30 \mathrm{~mL} ; \mathrm{n}=8$ ) breathed a mixture of $\mathrm{O}_{2}\left(\mathrm{I} \mathrm{L} \cdot \mathrm{min}^{-1}\right)$ and air $\left(\mathrm{I} \mathrm{L} \cdot \mathrm{min}^{-1}\right)$ and $\mathrm{G} 2$ (intracuff volume, $30 \mathrm{~mL}$; $\mathrm{n=8})$ a mixture of $\mathrm{O}_{2}\left(\mathrm{I} \mathrm{L} \cdot \mathrm{min}^{-1}\right)$ and $\mathrm{N}_{2} \mathrm{O}\left(\mathrm{I} \mathrm{L} \cdot \mathrm{min}^{-1}\right)$. Anesthesia was induced and maintained with pentobarbitone. LMA cuff pressure was measured at zero (control), 30, 60, 90 and I 20 min after \#4 LMA insertion. The dogs were sacrificed, and biopsy specimens from seven predetermined areas of the pharynx in contact with the LMA cuff were collected for light (LM) and scanning electron microscopic (SEM) examination by a blinded observer.

Results: LMA intracuff pressure decreased with time in GI ( $P$ $<0.00 \mathrm{I})$ and increased in G2 $(P<0.00 \mathrm{I})$. There was a significant difference between the groups $(P<0.00$ I $)$. In both groups, the LM study showed a normal epithelium covering the pharyngeal mucosa and mild congestion in the subepithelial layer. There were no differences between the groups $(P>0.10)$ or among the areas sampled $(P>0.05)$. In both groups, the SEM study showed a normal pharyngeal mucosa with mild superficial desquamation. Few specimens in $G$ I and $G 2$ showed more intense epithelial desquamation. Conclusion: High LMA intracuff pressures produced by $\mathrm{N}_{2} \mathrm{O}$ do not increase pharyngeal mucosal injury in dogs.
Objectif: Pendant l'anesthésie générale, le protoxyde d'azote $\left(\mathrm{N}_{2} \mathrm{O}\right)$ diffuse rapidement dans le ballonnet gonflable du masque laryngé $(M L)$, ce qui augmente la pression intraballonnet. II n'existe pas de corrélation évidente entre cette pression et la pression sur le pharynx. Nous avons étudié les effets de pressions élevées à l'intérieur du ballonnet du ML, secondaires au $\mathrm{N}_{2} \mathrm{O}$, sur la muqueuse pharyngée de chiens.

Méthode : Seize chiens de race commune ont été répartis au hasard en deux groupes: dans le Gl (volume intraballonnet, $30 \mathrm{~mL} ; n=8$ ) ils ont respiré un mélange de $\mathrm{O}_{2}\left(\mathrm{~L} \mathrm{~L} \cdot \mathrm{min}^{-1}\right)$ et d'air $\left(I \mathrm{~L} \cdot \mathrm{min}^{-1}\right)$ et dans e $\mathrm{G} 2$ (volume intraballonnet, $30 \mathrm{~mL} ; n=8)$ un mélange de $\mathrm{O}_{2}($ $\left.L \cdot \mathrm{min}^{-1}\right)$ et de $\mathrm{N}_{2} \mathrm{O}\left(\mathrm{L} \mathrm{L} \cdot \mathrm{min}^{-1}\right)$. L'anesthésie a été induite et maintenue avec du pentobarbital. La pression du ballonnet du ML a été mesurée à zéro, 30, 60, 90 et 120 min après l'insertion d'un ML no 4. Les chiens ont été sacrifiés. Les spécimens de biopsie de sept zones prédéterminées du pharynx en contact avec le ballonnet du Ml ont été recueillis pour un examen microscopique classique (MC) et électronque à balayage (MEB) réalisé par un examinateur impartial.

Résultats : La pression intraballonnet du ML a diminué avec le temps dans le GI $(P<0,001)$ et augmenté dans le $G 2(P<0,001)$. II n'y a pas eu de différence intergroupe significative $(P<0,001)$. Dans les deux groupes, l'examen MC a montré qu'un épithélium normal recouvrait la muqueuse pharyngée et qu'une congestion mineure existait dans la couche sous-épithéliale. Encore ici, il n'y a pas eu de différence intergroupe $(P>0,10)$ ou de différence entre les zones échantillonnées $(P>0,05)$. Dans les deux groupes, l'examen MEB a montré une muqueuse pharyngée normale et une desquamation superficielle légère. Peu de spécimens du GI et du G2 ont affiché une desquamation épithéliale plus importante.

From the Department of Anesthesiology, ${ }^{*}$ the Department of Otorhinolaryngology, Ophthalmology and Head and Neck Surgery, $\dagger$ the Department of Morphology of the Institute of Bioscience of the School of Medicine of the University of São Paulo (UNESP), Botucatu, São Paulo; and the Department of Pathology, $\$$ School of Medicine of the University Federal of Triângulo Mineiro, Uberaba, Minas Gerais, Brazil.

Address correspondence to: Dr. Tânia Mara Vilela Abud, Departamento de Anestesiologia, Faculdade de Medicina, UNESP, Distrito de Rubião Junior, Botucatu (SP), Brazil, ZIP CODE 18.618-970. Phone: 55 14 6802-6222; Fax 55 14 6822-4026; E-mail: anestesi@fmb.unesp.br

Accepted for publication March 2, 2001

Accepted for publication March
Revision accepted May 9, 2001 . 
Conclusion : Des pressions élevées à l'intérieur du ballonnet du ML, produites par le $\mathrm{N}_{2} \mathrm{O}$, n'augmentent pas la lésion de la muqueuse pharyngée chez les chiens.

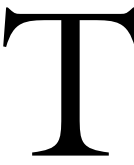

HE precise mechanical effects of the laryngeal mask airway (LMA) on the pharyngeal tissues are unknown. In theory, the inflated LMA cuff could generate sufficient pressure to cause a reduction in pharyngeal mucosal blood flow and induce compression of the mucosa against surrounding parts of the pharynx, such as the hyoid bone or cervical vertebra. On the other hand, the pharynx is a highly flexible structure that is normally subject to distortion and large pressure changes during swallowing and coughing.

The cuff of the LMA is manufactured from siliconebased rubber, a substance which is known to rapidly absorb nitrous oxide $\left(\mathrm{N}_{2} \mathrm{O}\right)$. During general anesthesia, $\mathrm{N}_{2} \mathrm{O}$ diffuses into the air-filled LMA cuff more rapidly than air can diffuse out of it, giving rise to an increase in cuff volume and pressure. ${ }^{1}$ There are a few case reports in the literature about nerve palsy and arterial compression after LMA use during anesthesia with nitrous oxide. ${ }^{2-5}$ The potential role of intracuff $\mathrm{N}_{2} \mathrm{O}$ diffusion has been discussed in these cases.

There is no clear correlation between LMA intracuff pressure and pressure on the pharynx. LMA cuff inflation with the recommended injection volume ${ }^{6}$ results in the residual volume of the cuff being exceeded and, in turn, likely to generate pressures exceeding the pharyngeal mucosal capillary perfusion pressure $(32 \mathrm{mmHg}){ }^{7}$ Although pressures on the mucosa with the LMA are generally lower than $32 \mathrm{mmHg}$, they can exceed this value in some locations at higher cuff volumes. ${ }^{8,9}$

The aim of the study was to investigate, by light microscopy (LM) and scanning electron microscopy (SEM), the effects of high LMA intracuff pressures secondary to the use of $\mathrm{N}_{2} \mathrm{O}$ on the pharyngeal mucosa in dogs.

\section{Materials and methods}

The trial was approved by the University Ethical Commission on Research in Animals. Ten male and six female mongrel dogs weighing 13 to $20 \mathrm{~kg}$ were studied. The dogs were determined to be healthy after clinical examination and normal red blood cell count. A previous study showed that a number 4 LMA was the best option for dogs of this size to effectively cover the larynx and provide an effective seal. ${ }^{10}$

Before anesthesia, an aneroid manometer (Tajiri Instrumental Co, Tokyo, Japan) was connected to a three-way stopcock to measure LMA intracuff pressure. Before each experiment, the device was calibrated against a mercury column. A three-way stopcock was connected to the LMA cuff pilot tube and opened to air so that intracuff pressure was at atmospheric pressure. A $50-\mathrm{mL}$ syringe was connected to the third port, and air in the cuff was completely evacuated as for insertion by the method described in man. ${ }^{6}$

After a 12-hr fast, a 20-gauge (G) catheter was placed in the cephalic vein of each dog, anesthesia induced by a bolus injection of $25 \mathrm{mg} \cdot \mathrm{kg}^{-1}$ of pentobarbitone, and maintained by an iv infusion of 3 $\mathrm{mg} \cdot \mathrm{kg}^{-1} \cdot \mathrm{hr}^{-1}$, using an infusion pump (Anne, Abbott, Chicago, USA). The LMA was inserted by the same anesthesiologist, according to a technique adapted from that previously reported in humans. ${ }^{6}$ Each dog was placed in the dorsal decubitus, head extended, and the tongue pulled forward. The LMA was inserted, with the dorsal side firmly supported against the hard palate until resistance was felt. The cuff was inflated with $30 \mathrm{~mL}$ of air and the cuff pressure was measured with the LMA in place. Correct positioning was verified in all cases using a $12 \mathrm{~cm} \mathrm{H}_{2} \mathrm{O}$ inspiratory pressure and the LMA adjusted until no air leak was observed without altering the intracuff pressure, and also by comparing inspired and expired tidal volumes. The LMA was then fixed to the mandible of the animal using a string.

The animals breathed spontaneously via a circle rebreathing system with absorption of carbon dioxide. Dogs were randomly (by opening a sealed envelope) allocated to two groups: Gl $(n=8)$ breathed a mixture of $1 \mathrm{~L} \cdot \mathrm{min}^{-1}$ of air and $\mathrm{l} \mathrm{L} \cdot \mathrm{min}^{-1}$ of oxygen and $\mathrm{G} 2$ $(n=8)$ a mixture of $1 \mathrm{~L} \cdot \mathrm{min}^{-1}$ of oxygen and $1 \mathrm{~L} \cdot \mathrm{min}^{-1}$ of $\mathrm{N}_{2} \mathrm{O}$.

Subsequently, a 20-G catheter was placed in the right femoral artery for blood pressure measurement (AS 3, Datex - Engstrom, Helsinki, Finland). An 18-G catheter was placed in the right jugular vein for infusion of 5 $\mathrm{mL} \cdot \mathrm{kg}^{-1} \cdot \mathrm{hr}^{-1}$ of lactated Ringer's solution. Pulse rate and arterial oxygen saturation were measured by pulse oximetry using a sensor placed on the tongue (4700 Oxicap, Ohmeda, Louisville, USA). The end-tidal carbon dioxide, respiratory rate and inspired fractions of oxygen and $\mathrm{N}_{2} \mathrm{O}$ were measured with a sidestream gas analyser (4700 Oxicap, Ohmeda, Louisville, USA). The sampling port was located between the proximal end of the LMA and the Y-piece of the anesthetic breathing system. Tidal volume was measured using a Mark 8 Wright respirometer (Ferraris, London, England) placed in the expiratory limb of the breathing system.

Anesthesia was maintained for two hours, and measurement of intracuff pressures was performed imme- 
diately after insertion of the LMA and 30, 60, 90 and 120 min thereafter.

At the end of the experiment, the dogs were sacrificed with an excessive dose of $i v$ pentobarbitone. The pharynx was removed with the LMA still in place, and biopsies of the mucosa taken from seven areas in contact with the LMA: hypopharynx (right and left side), piriform sinus (right and left side), arytenoid cartilage (right and left side), and cricoid cartilage. For SEM study, the specimens were fixed in $2.5 \%$ glutaraldehyde in a $0.1 \mathrm{M}$ sodium phosphate buffer solution ( $\mathrm{pH} 7.3$ ) for at least $24 \mathrm{hr}$. They were post-fixed in $2 \%$ osmium tetroxide solution in the same buffer for one hour and dehydrated in a graded concentration of ethanol. The samples were dried in a critical point apparatus using liquid carbon dioxide, mounted on a metal stub, sputter coated with gold and examined in a scanning electron microscope (Philips, Holland). For LM study the specimens were fixed in $10 \%$ formalin solution for at least $48 \mathrm{hr}$, included in paraffin, cut and stained with hematoxylin - eosin (H\&E).

All LM and SEM evaluation were carried out by a single pathologist blinded to the treatment group. In the LM analysis the following characteristics were evaluated: epithelial surface (erosion and neutrophilic inflammatory infiltration) and subepithelial layer (congestion, hemorrhage, and neutrophilic inflammatory infiltration). The analysis was semiquantitative with scoring from 0 to 3 (without, mild, moderate, or severe injury, respectively). The extent of epithelial erosion was scored from 0 to 3 ( $0=$ no erosion; $1=1 \%$ to $30 \% ; 2=31 \%$ to $60 \% ; 3=61 \%$ to $100 \%$ of the area eroded). The pharynx from three dogs euthanized with an excessive dose of iv pentobarbitone and without having been subjected to ventilation with a LMA were used as controls (G0 Group) for SEM evaluation.

A Student $t$ test was used for statistical comparison of the weight of the animals. Continuous data were compared using analysis of variance (ANOVA) for repeated measures followed by Tukey's test, in order to investigate differences over time. LM scores from each biopsy area were compared using the Mann-Whitney non parametric test for two independent samples. Comparisons between scores within each group were performed using the nonparametric test of Friedman, for dependent samples. A descriptive analysis was used for the SEM results. Data are reported as mean $\pm \mathrm{SD}$, and score results are presented as median (min-max). Probability levels less than 0.05 were considered significant.

\section{Results}

All LMA were inserted at the first attempt and a patent airway was obtained in all dogs. There were no

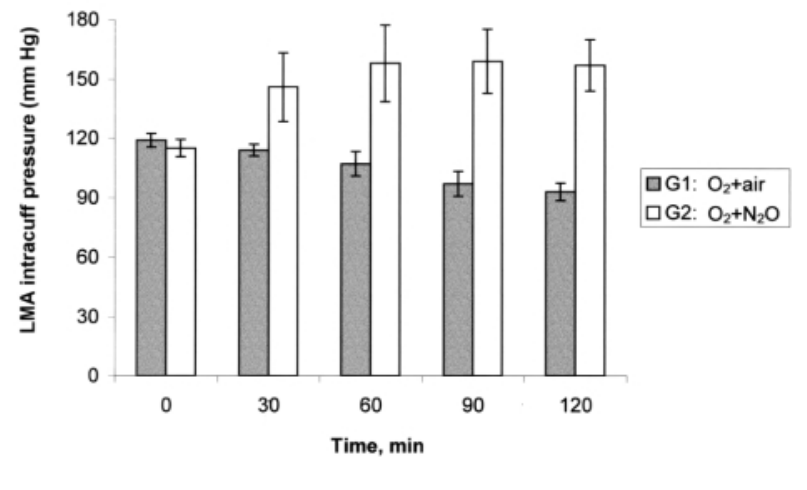

FIGURE 1 LMA intracuff pressures in Gl (fresh gas flow with oxygen + air) and G2 (fresh gas flow with oxygen + nitrous oxide). Mean \pm SD. Intracuff pressures were different between groups $(P<0.001$ by ANOVA). In Gl intracuff pressure decreased with time $(P<0.001)$ and in $\mathrm{G} 2$, intracuff pressure increased with time $(P<0.001$; treatment $x$ time effect; by ANOVA).

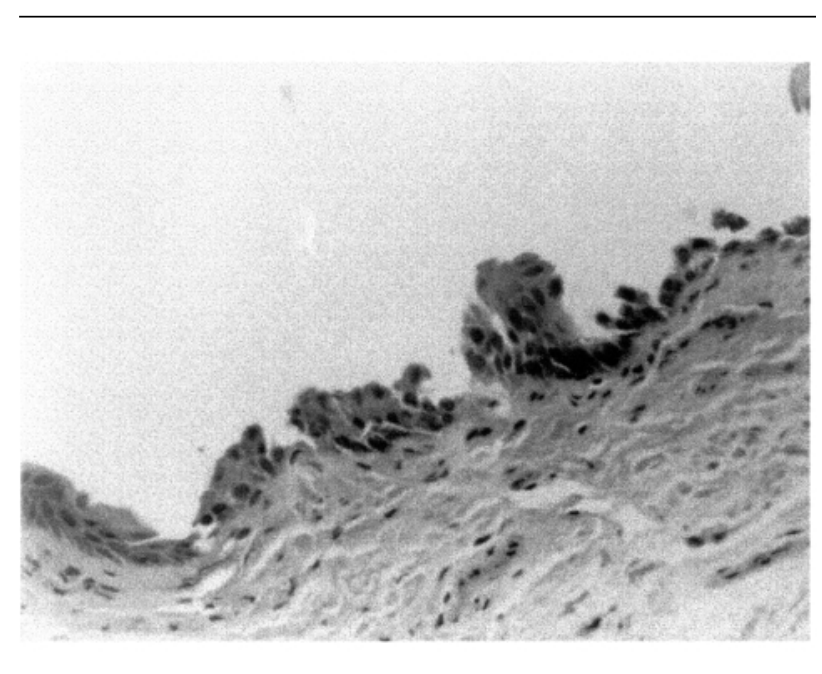

FIGURE 2 Group G2 (fresh gas flow with oxygen + nitrous oxide): segment of hypopharyngeal mucosa (right hypopharynxarea $2 \mathrm{r}$ ) showing epithelial desquamation without erosion (H\&E; $\mathrm{X} 80$ ).

dislodgements of the mask, and laryngospasm, cyanosis, regurgitation of gastric contents, or pulmonary aspiration were not observed during anesthesia. No blood was seen on the surface of the LMA after its removal.

There was no difference in the mean weight of the dogs between the two groups: Gl $(16.9 \pm 3.7 \mathrm{~kg})$ and G2 $(18.4 \pm 1.4 \mathrm{~kg})(P>0.10)$. 
TABLE Histologic results of congestion in the subepithelial layer of the laryngopharyngeal mucosa

\begin{tabular}{|c|c|c|c|}
\hline & & Group & \\
\hline & & G1 & G2 \\
\hline Hypopharynx & right $(2 \mathrm{r})$ & $\begin{array}{l}0 \\
(0-1)\end{array}$ & $\begin{array}{l}1 \\
(0-1)\end{array}$ \\
\hline & left $(2 \mathrm{l})$ & $\begin{array}{l}0.5 \\
(0-1)\end{array}$ & $\begin{array}{l}1 \\
(0-1)\end{array}$ \\
\hline Piriform sinus & right (3r) & $\begin{array}{l}0 \\
(0-1)\end{array}$ & $\begin{array}{l}1 \\
(0-1)\end{array}$ \\
\hline & left $(31)$ & $\begin{array}{l}0 \\
(0-1)\end{array}$ & $\begin{array}{l}1 \\
(0-1)\end{array}$ \\
\hline Arytenoid cartilage & right $(4 r)$ & $\begin{array}{l}0 \\
(0-1)\end{array}$ & $\begin{array}{l}1 \\
(0-1)\end{array}$ \\
\hline & left $(4 \mathrm{l})$ & $\begin{array}{l}0.5 \\
(0-1)\end{array}$ & $\begin{array}{l}0.5 \\
(0-1)\end{array}$ \\
\hline Cricoid cartilage & (5) & $\begin{array}{l}0 \\
(0-1)\end{array}$ & $\begin{array}{l}0 \\
(0-2)\end{array}$ \\
\hline
\end{tabular}

Data are median (minimum-maximum) for the score for congestion in the subepithelial layer ( $0=$ without; $1=$ mild; $2=$ moderate; $3=$ severe congestion). There was no difference between the groups $(P>0.10$ by Mann-Whitney's test $)$ and among the areas of each group $(P>0.05$ by Friedman's test).

LMA intracuff pressure decreased with time in Gl $(P<0.001)$, and it increased in $\mathrm{G} 2(P<0.001)$. A significant difference between intracuff pressures become apparent with time $(P<0.001)$ (Figure 1$)$.

In both groups, LM showed a normal stratified squamous epithelium covering the pharyngeal mucosa. Twenty- nine percent of specimens of G2 showed more intense epithelial desquamation (Figure 2). In both groups, no erosion was observed. Several specimens in Gl (35\%) and G2 (66\%) showed mild congestion in the subepithelial layer, but the difference either among the areas $(P>0.10)$ or between the groups $(P>0.05)$ was not statistically significant (Table I). Seven percent of specimens in G1 and 26\% in G2 showed mild neutrophilic inflammatory infiltration in the subepithelial layer, without significant differences either among the areas $(P>0.10)$ or between the groups $(P>0.10)$. No hemorrhage was detected.

In both groups, the SEM study showed a normal pharyngeal mucosa with mild superficial desquamation of the epithelium and areas with mucous filaments (Figure 3b). Large superficial layers of the epithelium were removed, leaving defects in the mucosal surface in $18 \%$ of the specimens in G2 (Figure 3c), and in $12 \%$ in Gl. The epithelial desquamation was more intense in $22 \%$ of specimens in G2 (Figure 3d) and in $16 \%$ in G1.

\section{Discussion}

In our study, LMA cuff inflation with the maximum recommended cuff volume $(30 \mathrm{~mL})$ produced, in both groups, an intracuff pressure above $100 \mathrm{mmHg}$. Similar values have been shown in previous studies in man. ${ }^{7,11-13}$ In both groups, the histologic findings in the subepithelial laver and epithelial surface of the pharyngeal mucosa, such as mild congestion and desquamation respectively, do not reflect mucosal damage, according to the pathologist's evaluation.

During administration of $\mathrm{N}_{2} \mathrm{O}$, LMA cuff pressures increased, as expected. Previous studies have shown that LMA intracuff pressure increases steadily during anesthesia with $\mathrm{N}_{2} \mathrm{O}$ and may reach $200 \mathrm{mmHg}$ or more on removal of the mask. ${ }^{1,7}$ These results show the importance of the rapid diffusion of $\mathrm{N}_{2} \mathrm{O}$ into the air-filled cuff. Control of the LMA cuff pressure should be performed, if not continuously, at least intermittently during anesthesia. Eventually, the large intracuff pressure generated with the LMA in place would increase the partial pressure of $\mathrm{N}_{2} \mathrm{O}$ within the cuff, decreasing the pressure gradient across the cuff wall, thereby limiting further diffusion. ${ }^{7,14}$ This can explain the stabilization of cuff pressures between times 60 and $120 \mathrm{~min}$, as compared to time $30 \mathrm{~min}$ (Figure 1).

Theoretically, the pressure exerted by the LMA cuff on the pharyngeal wall, may exceed the perfusion pressure of the pharyngeal mucosa. ${ }^{7,11,12}$ In recent studies in humans, pharyngeal mucosal pressures were recorded by microchip sensors at several sites on the LMA cuff. Mucosal pressures were generally much lower than those considered safe for the pharyngeal mucosa $(40$ $\mathrm{cm} \mathrm{H}_{2} \mathrm{O}$ ). The exerted pressure did not, in fact, dis- 

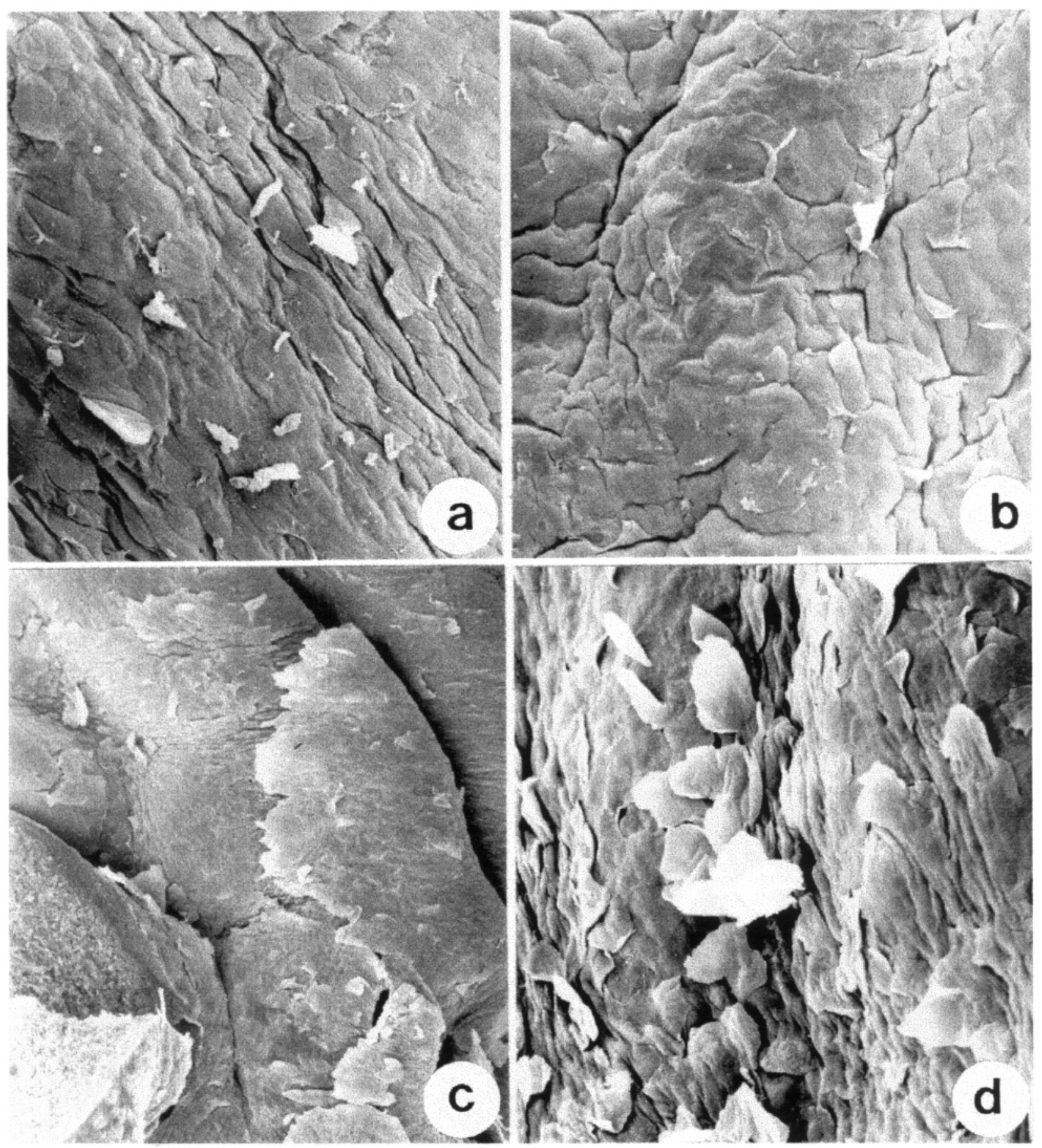

FIGURE 3 Segment of the right arytnoid cartilage (area 3r) showing: a, G0 (control) - normal mucosa with mild superficial desquamation of the epithelium with mucous filaments (SEM; X 1960); b, Gl (fresh gas flow with oxygen + air) normal mucosa with mild superficial desquamation of epithelium and mucous filaments (SEM; X 1083); c, G2 (fresh gas flow with oxygen + nitrous oxide) large superficial layers of the epithelium leaving defects in the mucosal surface (SEM; X 375); d, G2: mucosa with intense epithelial desquamation ( SEM; X 1690). 
tribute evenly on the pharynx, and the pressure exerted by the proximal part of the cuff was considerably higher. ${ }^{8,9,15}$ Nevertheless, direct measurement indicates that the pressure exerted on the mucosa generally increases with increasing cuff volumes. ${ }^{8,9}$

The upper airway anatomy of a dog is not the same as that of a humans, but the histological structure of the pharyngeal tissues is similar. ${ }^{16}$ The laryngopharyngeal mucosa is covered by a stratified squamous epithelium composed of several layers of flattened cells undergoing constant proliferation, maturation, and loss. This ephithelium is much more resistant to injuries than the ciliated pseudostratified respiratory epithelium which covers the trachea. We surmise that absence of major pharyngeal injuries in this study is related to the resilent nature of this epithelium combined with the mechanical properties of the pharynx, which is well adapted to large physiological pressure and volume changes, and the short duration of the study (two hours). We are unaware of histological studies with the LMA in situ for a longer period.

Studies in humans have shown that the position of the LMA is not always ideal, even when function is good. ${ }^{17}$ Sub-optimal positioning could result in compression of the pharyngeal tissues against rigid structures, such as the hyoid bone or cervical column, explaining the lingual, hypoglossal, or recurrent laryngeal nerve palsy and compression of the lingual artery sometimes seen after use of the LMA, during anesthesia with $\mathrm{N}_{2} \mathrm{O} .^{2-5}$ The potential role of high intracuff pressures, produced by overinflation of the cuff or intracuff $\mathrm{N}_{2} \mathrm{O}$ diffusion, was discussed in these cases but pressures had not been measured. Brain pointed out that the published inflation values represent maximum volumes and recommended not inflating the LMA cuff above a pressure of $60 \mathrm{~cm} \mathrm{H}_{2} \mathrm{O}$, in order to diminish the possibility of nervous or arterial compression. ${ }^{18}$

Studies have investigated whether the removal of gas from the LMA cuff changes the incidence of pharyngeal complaints after surgery. ${ }^{19-22}$ In the majority of these studies, removal of gas from the LMA cuff to the minimum level required for an effective pressure $\left(60 \mathrm{~cm} \mathrm{H} \mathrm{H}_{2} \mathrm{O}\right)$ decreased the incidence of sore throat after surgery. ${ }^{19-21}$ In contrast, in another study, the differences in LMA cuff pressures did not influence either the incidence or the severity of laryngopharyngeal complaints. ${ }^{22}$

In our study, factors other than intracuff pressure that might have influenced the development of pharyngeal mucosal alterations were excluded. Animals were maintained normotensive throughout the study. The same LMA was used in all cases and was inserted by a single experienced investigator. Lubrificants were not used to facilitate insertion. Anesthetic depth during insertion was adequate in all dogs to provide smooth placement of the LMA. Correct location of the LMA is easier in the dog than in humans, since the angle between the mouth and the oropharyngeal cavity is smaller and the mouth opens more than in humans.

In conclusion, high LMA intracuff pressures produced by $\mathrm{N}_{2} \mathrm{O}$ do not increase pharyngeal mucosal injury in dogs.

\section{Acknowledgement}

This study was financed by a grant from "Fundação de Amparo à Pesquisa do Estado de São Paulo (FAPESP)", São Paulo, Brazil.

\section{References}

1 Lumb $A B$, Wrigley $M W$. The effect of nitrous oxide on laryngeal mask cuff pressure. In vitro and in vivo studies. Anaesthesia 1992; 47: 320-3.

2 Laxton $\mathrm{CH}$. Lingual nerve paralysis following the use of the laryngeal mask airway. Anaesthesia 1996; 51 : 869-70.

3 King C, Street MK. Twelfth cranial nerve paralysis following use of a laryngeal mask airway. Anaesthesia 1994; 49: 786-7.

4 Cros AM, Pitti R, Conil C, Girand D, Verhulst J. Severe dysphonia after use of a laryngeal mask airway. Anesthesiology 1997; 86: 498-500.

5 Wynn JM, Jones KL. Tongue cyanosis after laryngeal mask airway insertion (Letter). Anesthesiology 1994; 80: 1403-4.

6 Brain AIJ. The laryngeal mask - a new concept in airway management. Br J Anaesth 1983; 55: 801-4.

7 Marjot R. Pressure excerted by the laryngeal mask airway cuff upon the pharyngeal mucosa. Br J Anaesth 1993; 70: 25-9.

8 Brimacombe J, Keller C. A comparison of pharyngeal mucosal pressure and airway sealing pressure with the laryngeal mask airway in anesthetized adult patients. Anesth Analg 1998; 87: 1379-82.

9 Keller C, Brimacombe J. Pharyngeal mucosal pressures, airway sealing pressures, and fiberoptic position with the intubating versus the standard laryngeal mask airway. Anesthesiology 1999; 90: 1001-6.

10 Braz JRC, Martins RHG, Mori AR, Luna SPL. Investigation into the use of laryngeal mask airway in pentobarbital anesthetized dogs. Vet Surg 1999; 28 : 502-5.

11 Asai T, Howell TK, Koga K, Morris S. Appropriate size and inflation of the laryngeal mask airway. $\mathrm{Br} \mathrm{J}$ Anaesth 1998; 80: 470-4.

12 O'Kelly SW, Heath KJ, Lawes EG. A study of laryngeal mask inflation. Pressures exerted on the pharynx. 
Anaesthesia 1993; 48: 1075-8.

13 Brimacombe J, Berry A. Laryngeal mask airway cuff pressure and position during anaesthesia lasting one to two hours. Can J Anaesth 1994; 41: 589-93.

14 Stanley TH. Nitrous oxide and pressures and volumes of high- and low-pressure endotracheal-tube cuffs in intubated patients. Anesthesiology 1975; 42: 637-40.

15 Keller C, Brimacombe J, Benzer A. Calculated versus measured pharyngeal mucosal pressures with the laryngeal mask airway during cuff inflation: assessment of four locations. Br J Anaesth 1999; 82: 399-401.

16 Watanabe I. Scanning Electron Microscopy Atlas of Cells and Tissues of the Oral Cavity, $1^{\text {st }}$ ed., São Paulo: FAPESP-CNPQ Publishers, 1998.

17 Keller C, Pühringer F, Brimacombe JR. Influence of cuff volume on oropharyngeal leak pressure and fibreoptic position with the laryngeal mask airway. $\mathrm{Br} \mathrm{J}$ Anaesth 1998; 81: 186-7.

18 Brain AIJ. Pressure in laryngeal mask airway cuffs (Letter). Anaesthesia 1996; 51: 603.

19 Burgard G, Möllhoff T, Prien T. The effect of laryngeal mask cuff pressure on postoperative sore throat incidence. J Clin Anesth 1996; 8: 198-201.

20 Nott MR, Noble PD, Parmar M. Reducing the incidence of sore throat with the laryngeal mask airway. Eur J Anaesthesiol 1998; 15: 153-7.

21 Brimacombe J, Holyoake J, Keller C, et al. Emergence characteristics and postoperative laryngopharyngeal morbidity with the laryngeal mask airway: a comparison of high versus low initial cuff volume. Anaesthesia 2000; 55: 338-43.

22 Rieger A, Brunne B, Striebel HW. Intracuff pressures do not predict laryngopharyngeal discomfort after use of the laryngeal mask airway. Anesthesiology 1997; 87: 63-7. 